\title{
IMRT for Orbital MALT Lymphoma: A Case Report and a Review of the Literature
}

Kanyilmaz Gul*, Koc Mehmet, Aktan Meryem, Temiz Selami Aykut and Demir Hikmettin

Necmettin Erbakan University Meram Medicine School, Department of Radiation Oncology, Akyokus Mevkii, Konya, Turkey

\begin{abstract}
Orbital lymphoma is rare and accounts for less than $1 \%$ of non-Hodgkins lymphomas (NHLs) throughout the body. Marginal zone B-cell lymphoma of the mucosa-associated lymphoid tissue (MALT) type ise the most common histological type involving the orbit. MALT lymphomas are indolent, and usually respond well to local radiotherapy (RT). Results from RT series demonstrated excellent and durable local control and survival rates in patients with localized orbital MALT lymphoma. However, due to the rarity of the disease, data about optimal radiation dose from comparative studies are not available and, moreover, in reports with a substantial number of treated patients, doses in the range of 20 and $57 \mathrm{~Gy}$ were found to be used. The optimal radiation dose for treating this tumor is controversial. This case is presented because of rare incidence of orbital maltoma and to evaluate the effectiveness of RT in our Radiation Oncology department.
\end{abstract}

Keywords: Lymphoma; Orbital maltoma; Radiotherapy; IMRT

\section{Case Presentation}

A 68 years old man presented with a slow growing mass arising from the left orbit (Figure 1). Visual acuity and visual field defects were normal in ophthalmological examination but increase retrobulber tissue density were detected in the left ocular ultrasonography. In a exophthalmos metric measuring the right eye was $17 \mathrm{~mm}$ and the left eye was measured as $26 \mathrm{~mm}$. The right eye was normal on examination. There were no enlarged lymph nodes and no significant findings on systemic examination. Routine blood investigations were within normal limits. Orbital magnetic resonance imaging (MRI) was performed to evalution of left retrobulbar mass (Figure 2). Incisional biopsy was performed after MRI. The patient had biopsy-proven MALT lymphoma and was classified according to the World Health Organization (WHO) classification [1].

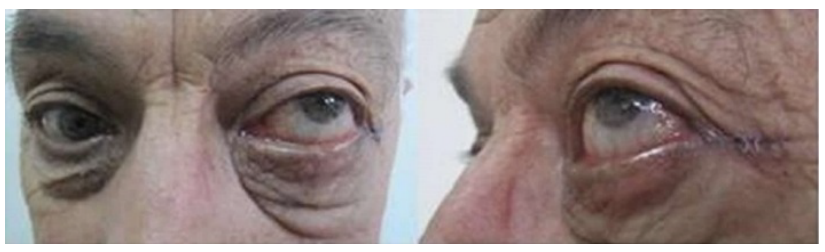

Figure 1: The appearance of patient before treatment.

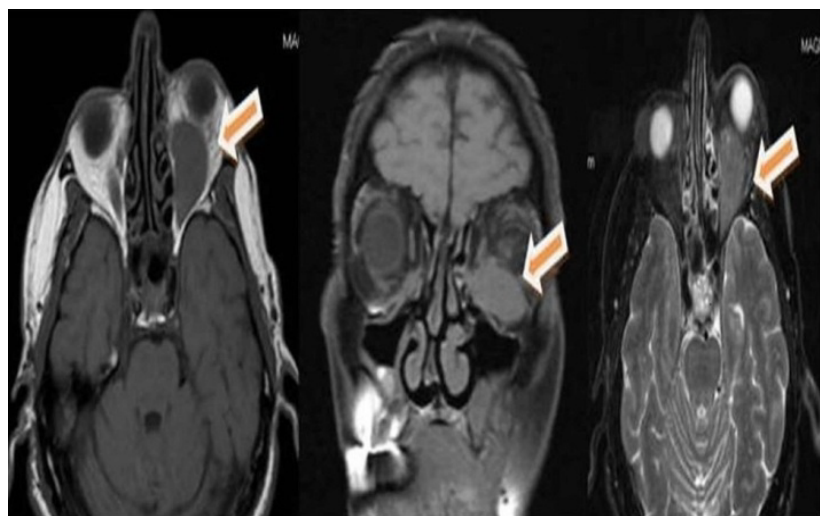

Figure 2: Images of pretreatment MRI.
Immunological phenotyping on parafin sections was performed for demonstration of light chain restriction and the phenotype CD20+, CD5-, CD10-, CD23, cyclin D1-, and ki-67 proliferation index was $5-10 \%$, in context with a microscopic appearance, is consistent with an indication of a MALT lymphoma. Furthermore, a PET-CT scan was performed on the patient. Because of the absence of another focus in PET-CT, the patient was considered stage $1 \mathrm{E}$ and included in curative RT program.

The study was conducted according to the ethical principles of the latest version of Helsinki Declaration.

\section{RT Treatment}

Patients head was immobilized with a thermoplastic mask before CT simulation. The structures at risk (right and left eye, right and left lens, right and left lacrimal gland, right and left optic nerve and optic chiasm) were contoured. The whole orbital socket was included in the Clinical Target Volume (CTV). An isocentric multibeam technique with inverse optimization was used to deliver specified doses to the Planning Target Volume (PTV). The dose was prescribed such that $>95 \%$ of the PTV received $100 \%$ of the prescribed dose. RT delivered 36 Gy at 1.8 Gy per fraction by intensity-modulated radiotherapy (IMRT) technique.

\section{Side Effects}

Acute and late ocular side effects were evaluated and graded according to RTOG toxicity score. There was no significant acute toxicity developed. Only mild conjunctivitis determined in second treatment week, which can managed by symptomatically. At the moment both eyes

*Corresponding author: Kanyilmaz Gul, Necmettin Erbakan University Meram Medicine School, Department of Radiation Oncology, Akyokus Mevkii, Konya, Turkey, 42090, Tel: +905056104203; E-mail: drgulgun@yahoo.com

Received: October 21, 2015; Accepted: November 06, 2015; Published: November 09, 2015

Citation: Gul K, Mehmet K, Meryem A, Aykut TS, Hikmettin D (2015) IMRT for Orbital MALT Lymphoma: A Case Report and a Review of the Literature. Oncol Cancer Case Rep 1:103.

Copyright: (c) $2015 \mathrm{Gul} \mathrm{K}$, et al. This is an open-access article distributed under the terms of the Creative Commons Attribution License, which permits unrestricted use, distribution, and reproduction in any medium, provided the original author and source are credited. 
examination were normal in ophthalmological examination (Figure 3). Patients are under follow-up and have remained free of recurrence or systemic dissemintion after 30 months of RT (Figure 4).

\section{Discussion}

Orbital lymphoma is rare and accounts for less than $1 \%$ of nonHodgkins lymphomas (NHLs) throughout the body, and marginal zone B-cell lymphoma of the mucosa-associated lymphoid tissue (MALT) type ise the most common histological type involving the orbit $[2,3]$. For Stage I and II localized disease process, radiation therapy is the primary modality of treatment. Treatment of orbital lymphoma with radiotherapy is challenging because of the radiosensitive lens, lacrimal gland, and retina, which are located near or within the target volume.

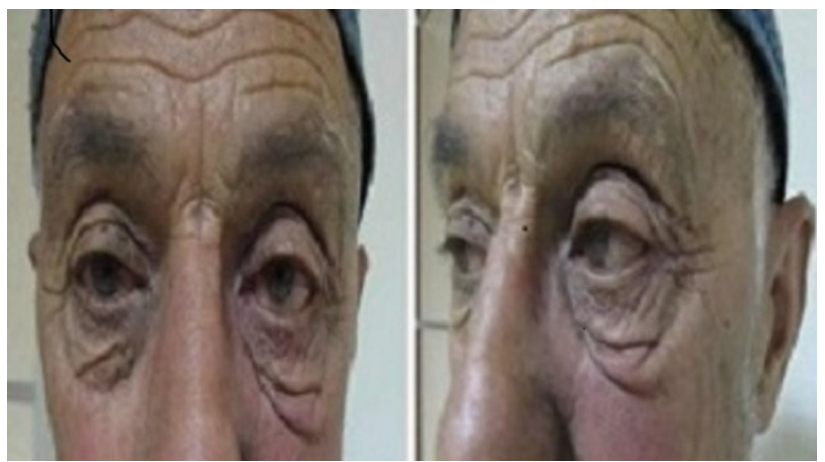

Figure 3: The appearance of patient after treatment.

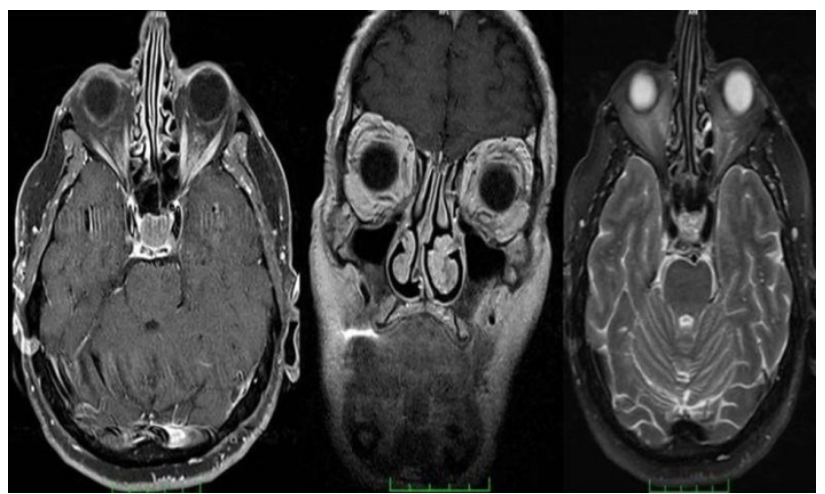

Figure 4: Images of posttreatment MRI

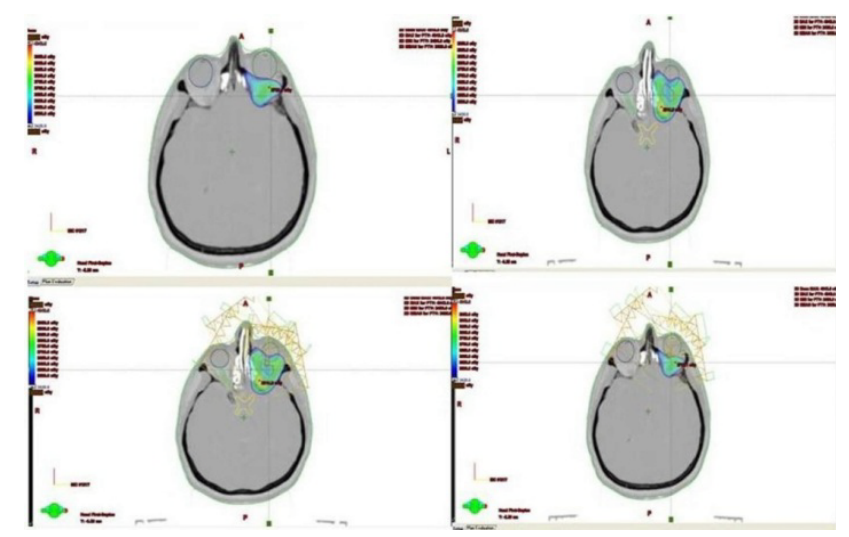

Figure 5: IMRT plan of left oculer maltoma.
Field arrangements vary depending on the exact location of the disease. Local control for orbital lymphoma with primary radiotherapy is excellent. Long-term control rates in literature range from $89 \%$ to $100 \%$ [4-8]. A series of orbital maltomas reported by Bischof et al. [9] showed no local relapse in their 26 stage I patients. RT was given five times weekly, 1.8-2 Gy per fraction and totally $30 \mathrm{~Gy}$ delivered. All of the 26 stage I patients had a complete response after radiotherapy. The 5-year recurrence free survival rate was $100 \%$. They observed 2 systemic relapses and the actuarial 5 -year freedom from distant relapse rate was $90 \%$. The median overall survival for the patients in stage I was 56 months (range 8-138 months). There was no death in their cohort was related to lymphoma, resulting in a disease-specific survival of $100 \%$. There is no consensus regarding the optimal radiotherapy dose for patient with MALT lymphoma of orbit. A number of studies were based on retrospective data, and the range of radiation dose was wide because it took a relatively long time to collect sufficient clinical cases to analyze because of the rarity of orbital MALT lymphoma. Radiotherapy with a dose of 30-35 Gy has been reported to be sufficient to provide local control and cure in localized orbital MALTOMA [7,10] Fung et al. [4] reported a significant dose-response relationship in MALT lymphoma of ocular adnexa; the 5-year local control rate was $86 \%$ for less than 30 Gy and $100 \%$ for 30 Gy or more. Lee et al., [11] demonstrated that excellent local control and survival can be achieved for patients with stage I MALT lymphoma of orbita by radiotherapy alone with a median dose of $30 \mathrm{~Gy}$. In our study, we treated with RT with a total dose $36 \mathrm{~Gy}$ with IMRT technique.

In addition to local disease control, treatment of orbital lymphoma should consider the functional preservation of the eye. Acute radiationinduced conjunctivitis developed in our patient which can managed by symptomatically. Cataract is the most common late complication. We know that the lens is very sensitive to radiation. As little as $2 \mathrm{~Gy}$ in a single fraction [12] or 10-12 Gy in 1.5-2.0 Gy fractions [13] delivered to the lens can significantly increase the incidence of cataract formation. At higher doses, cataract formation is inevitable.

In old series, carefully applied lens shielding was important to prevent the formation of cataract, but if inappropriately applied, it could compromise target volume coverage, and a sufficient radiation dose may not be delivered. As a consequence, inappropriate lens shielding may result in a lower response rate and a higher local relapse rate [14]. Goda et al., [15] reported that incidence of Grade 3 cataract at 7 years was $25 \%$. in their 89 patients with Stage IE POML received RT. Uno et al., [16] reported that $32 \%$ of the patients experienced cataracts because lens shielding techniques were used for only $48 \%$ of the patients; however, other studies report only a $0 \%-12 \%$ rate of cataract formation [11,14,16-18]. With the advent of accurate imaging modalities and the evolution in RT delivery technique that allows delivery of precision RT (e.g., image guided RT), a question is raised whether irradiating the orbit partially will be acceptable as it may further reduce both acute and longterm toxicities. In our department we use IMRT technique, so $36 \mathrm{~Gy}$ could be performed to the target volume without exceeding the critical organ doses (such as lens, lacrimal gland and conjunctiva). In our study maximum dose of left lens is $760 \mathrm{cGy}$ and also mean dose of left lens is $426 \mathrm{cGy}$ (Figure 5).

The role of surgery in the treatment of orbital lymphoma is limited to biopsy and extensive surgical excisions should be avoided. Surgery alone is seldom used except for conjunctival lesions. There is a high relapse rate after surgery as reported by some authors. This high recurrence rate may project difficulty in performing a radical surgery and preserving function. Esik et al., [6] compared different modalities 
Citation: Gul K, Mehmet K, Meryem A, Aykut TS, Hikmettin D (2015) IMRT for Orbital MALT Lymphoma: A Case Report and a Review of the Literature. Oncol Cancer Case Rep 1:103.

for the treatment of orbital NHL. They reported $0 \%$ local relapse-free survival at 10 years in patients treated with surgery alone. Forty-two percent $(42 \%)$ of them receiving surgery plus chemotherapy relapsed locally, but the 10-year local relapse-free survival in the primary radiotherapy group was $100 \%$. Local relapses after surgery alone can be effectively treated with radiotherapy leading to complete response; but, the cosmetic outcome may be worsened by two therapies.

Furthermore, the role of chemotherapy in the treatment of indolent stage IE orbital lymphoma is limited. Local control reported in a retrospective series with chemotherapy was only $42 \%$ as compared to $100 \%$ with radiotherapy alone [6]. Thus, the overall survival may be worse after primary chemotherapy (even with salvage radiotherapy) than when radiotherapy is performed as initial treatment. Because of this and the potential side-effects of chemotherapy in elderly patients there is no indication for primary chemotherapy, in early stage localized low-grade disease. But, it has a definitive role in high-grade tumors or those with systemic manifestations of low grade and intermediate lesions.

Role of antibiotics is not yet well defined in orbital lymphomas as for MALT of the stomach because of the different biological nature of these tumors. In a meta-analysis, Husain et al., [19] suggested a striking variability in the association between $C$ psittaci and orbital lymphoma across geographic regions and even between studies from the same geographic regions. Antibiotics have an unproven role against orbital lymphoma based on the lack of objective methods of assessment of response in the majority of reports, lack of stratification of response rates based on histologic subtypes of orbital lymphoma and short followup time. Future confirmatory, large prospective trials with standard objective response criteria and a larger follow-up period is warranted to confirm whether this fast, cheap, and well-tolerated therapy could replace other more aggressive strategies as first-line treatment against orbital lymphoma

\section{Conclusion}

Lymphomas of the orbit are uncommon and may involve any site in the orbit. Full staging work up is mandatory for proper management. Local radiotherapy is an excellent treatment modality for primary orbital lymphoma. According to previous data and the result of our experience, we currently use doses of $36 \mathrm{~Gy}$ in patients with indolent NHL to achieve an optimal local control and to minimize the risk of complications. Treatment using with IMRT technique will be acceptable as it may further reduce both acute and long-term toxicities.

\section{References}

1. Jaffe ES, Harris NL, Stein H, Vardiman JW (2001) WHO classification: tumors of hematopoietic and lymphoid tissues. World Health Organization of Tumor series. Lyon IARC Press.
2. Fitzpatrick PJ, Macko S (1984) Lymphoreticular tumors of the orbit. Int J Radiat Oncol Biol Phys 10: 333-340

3. Margo CE, Mulla ZD (1998) Malignant tumors of the orbit. Analysis of the Florida Cancer Registry. Ophthalmology 105: 185-190.

4. Fung CY, Tarbell NJ, Lucarelli MJ, Goldberg SI, Linggood RM, et al. (2003) Ocular adnexal lymphoma: clinical behavior of distinct World Health Organization classification subtypes. Int J Radiat Oncol Biol Phys 57: 13821391.

5. Dunbar SF, Linggood RM, Doppke KP (1990) Conjunctival lymphoma: results and treatment with a single anterior electron feld. A lens sparing approach. Int J Radiat Oncol Biol Phys 19: 249-257.

6. Esik O, Ikeda H, Mukai K (1996) A retrospective analysis of different modalities for treatment of primary orbital non-Hodgkin's lymphoma. Radiother Oncol 38 : $13-18$

7. Smitt MC, Donaldson SS (1993) Radiotherapy is successful treatment for orbital lymphoma. Int J Radiat Oncol Biol Phys 26: 59-66.

8. Stafford SL, Kozelsky TF, Garrity JA (2001) Orbital lymphoma: radiotherapy outcome and complications. Radiother Oncol 59: 139-144.

9. Bischof M, Karagiozidis M, Krempien R (2007) Radiotherapy for Orbital Lymphoma. Strahlenther Onkol 183: 17-22.

10. Lee SW, Suh CO, Kim GE (2002) Role of radiotherapy for primary orbital lymphoma. Am J Clin Oncol 25: 261-265.

11. Lee JL, Kim MK, Lee KH, Hyun MS, Chung HS, et al. (2005) Extranodal marginal zone B-cell lymphomas of mucosa-associated lymphoid tissue-type of the orbit and ocular adnexa. Ann Hematol 84: 13-18

12. Deeg HJ, Flournoy N, Sullivan KM (1984) Cataracts after total body irradiation and marrow transplantation: A sparing effect of dose fractionation. Int J Radiat Oncol Biol Phys 10: 957-964.

13. Henk JM, Whitelocke RA, Warrington AP (1993) Radiation dose to the lens and cataract formation. Int J Radiat Oncol Biol Phys 25: 815-820.

14. Suh CO, Shim SJ, Lee SW (2006) Orbital marginal zone B-cell lymphoma of MALT: Radiotherapy results and clinical behavior. Int J Radiat Oncol Biol Phys 65: 228-233.

15. Goda JS, Le LW, Lapperrıere NJ, Mıllar BA, Payne D, et al. (2011) Localized orbital mucosa-associated lymphoma tissue lymphoma managed with prımary radiation therapy: effıcacy and toxicity. Int J Radiation Oncology Biol Phys 81: 659-666.

16. Uno T, Isobe K, Shikama N (2003) Radiotherapy for extranodal, marginal zone B-cell lymphoma of mucosa-associated lymphoid tissue originating in the ocular adnexa: A multiinstitutional, retrospective review of 50 patients. Cancer 98: 865-871.

17. Le QT, Eulau SM, George TI (2002) Primary radiotherapy for localized orbital MALT Iymphoma. Int J Radiat Oncol Biol Phys 52: 657-663.

18. Tsang RW, Gospodarowicz MK, Pintilie M (2003) Localized mucosa-associated lymphoid tissue lymphoma treated with radiation therapy has excellent clinical outcome. J Clin Oncol 21: 4157-4164.

19. Husain A, Roberts D, Pro B, McLaughlin P, Esmaeli B (2007) Meta-analysis of the association between Chlamydia psittaci and ocular adnexal lymphoma and the response of ocular adnexal lymphoma to antibiotics. Cancer 110: 809-815. 